\title{
COMMENT
}

\section{Partnering with youth in community-based participatory research to address violence prevention}

\author{
Benjamin J. Oldfield ${ }^{1}$, Barbara J. Tinney ${ }^{2}$ and James M. Dodington ${ }^{3}$ \\ Pediatric Research (2018) 84:155-156; https://doi.org/10.1038/s41390-018-0074-0
}

Just days after a gunman turned Marjory Stoneman Douglas High School into a frantic crime scene in February 2018, student survivors from the Florida school organized a youth movement for stricter gun laws. With sleeping bags and permission slips, they bussed to the State Capitol, pursued lawmakers, and have taken the world stage with the articulate message that they are fed-up with the inability of adult leaders to protect students in classrooms like theirs. The students' voices seem to have risen above a decades-long stalemate about gun laws, drawing policymakers away from deadlock and towards dialog. This may be partly due to the emotional response to images of young people speaking out for their safety, but it also reflects the exceptionality of today's young people as the American generation that is the most racially and ethnically diverse, most technologically interconnected, and (at least for now) least habituated to the standstill in debate around firearms.

Their message is powerful intrinsically, but it is also a powerful demonstration of how youth (which we are defining as school-age children and adolescents) can impact health policy. Researchers seeking to inform policy with their work should take note. Reducing harm from gun violence through research and legal reform are well-supported strategies in public health literature, and one way to move these strategies toward action is to include those primarily impacted by gun violence in research and implementation efforts: youth and members of racial and ethnic minority communities. ${ }^{1}$ Unfortunately, members from these groups tend to be absent from research and policy conversations. ${ }^{2}$

A first step toward including youth in research and implementation is to support research on topics relevant to them. Recently, the National Institutes of Health made a move in the right direction by announcing that researchers are required to report the ages of participants in clinical research studies funded by the agency, starting in 2019. This change will allow for greater scrutiny of (and advocacy for) studies that address children and adolescents, and it will facilitate the aggregation of data across studies.

In addition to dedicating resources to pediatric research, funders and policymakers should also focus on research that incorporates the perspectives of those most impacted by gun violence. Our local experiences have taught us that research with adolescents -in partnership with them as co-investigators-can increase the relevance of research findings. One way investigators can partner with young people is by using a community-based participatory research (CBPR) approach, which centers around equitable partnerships between academicians and community organizations or community members. ${ }^{3}$ Building a platform for research alongside youth, particularly those in racial and ethnic minority communities (those who are most impacted by gun violence), is an important prerequisite for solutions to this complicated epidemic. Moreover, youth-partnered CBPR can yield not only important contributions to science and policy, but also benefits to youth participants themselves.

Our team has been involved in CBPR in New Haven, CT, over the last 7 years that has examined the experiences of high-school and junior high-school aged individuals around violence and its prevention, and depended on the partnership between a group of researchers (including author J.M.D.) and a community-based organization (CBO, directed by B.J.T). Over the years, high-school students from racial and ethnic minority communities developed skills with which to collect, analyze, and disseminate data that was relevant to them and their neighborhoods. For example, they discussed the root causes of violence using a problem-tree analysis, used their own photography to set the context for focus groups with their peers (photoelicitation), then considered the specific impact of violence on girls. ${ }^{4}$

The research projects also supported programming that was designed to build skills and foster networking among the youth, such as a several-weeks-long summer training on community organizing, research, and leadership. They presented their study results in various forums, including at the New Haven Police Department, City Hall, and to their peers in the school system, in events that exposed them to civic participation as young citizens. One consequence of their work was the development of a citywide policy for violence prevention that supported programs informed by the data they had collected. Some students cited their research as a primary reason for pursuing further education. Celebrating their expertise and facilitating positive interactions with adults in leadership positions, it seemed, was contributing to their healthy development.

Despite experiences such as ours, engaging youth in the design and dissemination of health-related research is uncommon. For example, authors of a 2013 systematic review on the involvement of youth in research found that only $15 \%$ of studies in which investigators claimed youth-engagement actually did so using a CBPR framework. ${ }^{5}$ Only a fraction of studies engaged youth as partners in research design or the interpretation of findings. More commonly, when they are involved at all, youth assist as data collectors. ${ }^{5}$

Partnering with youth in research poses logistical and ethical challenges to investigators. Trusting partnerships between academicians and community members take time to develop, particularly when one of these partners is a group of youth. The

\footnotetext{
${ }^{1}$ National Clinician Scholars Program, Yale School of Medicine, New Haven, CT, USA; ${ }^{2}$ New Haven Family Alliance, New Haven, CT, USA and ${ }^{3}$ Department of Pediatrics, Yale School of Medicine, New Haven, CT, USA

Correspondence: Benjamin J. Oldfield (benjamin.oldfield@yale.edu)
}

Received: 21 March 2018 Revised: 14 May 2018 Accepted: 21 May 2018 Published online: 13 June 2018 
timeline of a high-school student, punctuated as it is by school, transportation challenges, and jobs outside of school, may not map well onto a researcher's schedule or academic grant cycles. And young people's time needs to be compensated at least as much as it would be if they held service jobs, as many of them do, to support their needs and expose research as a potential career avenue. To overcome these hurdles, partnering with a $\mathrm{CBO}-$ via strategic partnerships at the "adult" level-provides a trusting infrastructure in which to engage youth in research design and conduct. Research funders are increasingly recognizing the importance of these partnerships and are in early stages of developing funding mechanisms that allow for the iterative processes needed in collaborations with community organizations. These processes always require developing trust, research skills, and the mutual recognition of the value all partners bring to the research before developing research aims.

The Parkland, FL, students have demonstrated their potential to be organized and impactful. Their generation's racial and ethnic diversity, technological savvy, and particular focus on violence argue for their inclusion in our efforts to promote healthier and safer communities. Researchers, funders, and $\mathrm{CBO}$ s should formalize strategies that facilitate trust-building and partnership formation among academicians and youth, particularly those youth from racial and ethnic minority communities. Together, we should craft youth-focused, evidence-based approaches to problems like gun violence so that the youth can contribute to science as well as become stronger actors in their communities in our collective effort to improve children's health.

\section{FUNDING}

This project was funded by the Department of Veterans' Affairs' Office of Academic Affiliations through the National Clinician Scholars Program.

\section{AUTHOR CONTRIBUTION}

B.J.O., B.J.T., and J.M.D. conceptualized the argument, drafted the initial manuscript, and reviewed and revised the manuscript.

\section{ADDITIONAL INFORMATION}

Competing interests: The authors declare no competing interests.

Publisher's note: Springer Nature remains neutral with regard to jurisdictional claims in published maps and institutional affiliations.

\section{REFERENCES}

1. Srinivasan, S., Mannix, R. \& Lee, L. K. Epidemiology of paediatric firearm injuries in the USA, 2001-2010. Arch. Dis. Child. 99, 331-335 (2014).

2. Wray-Lake, L. \& Hart, D. Growing social inequalitites in youth civic engagement? Evidence from the National Election Study. Polictical Sci. Polit. 45, 456-461 (2012).

3. Israel, B. A., et al., Eds. Methods in Community-based Participatory Research for Health. 1st ed (Jossey-Bass, San Francisco, CA, 2005).

4. Hansen, L. O. et al. "You get caught up": youth decision-making and violence. J. Prim. Prev. 35, 21-31 (2014).

5. Jacquez, F., Vaughn, L. M. \& Wagner, E. Youth as partners, participants or passive recipients: a review of children and adolescents in community-based participatory research (CBPR). Am. J. Community Psychol. 51, 176-189 (2013). 